\title{
STUDIES ON FREE ERYTHROCYTE PROTOPORPHYRIN, SERUM IRON, SERUM IRON-BINDING CAPACITY AND PLASMA COPPER DURING NORMAL PREGNANCY ${ }^{1}$
}

\author{
By JANE FAY, G. E. CARTWRIGHT, AND M. M. WINTROBE \\ (From the Department of Medicine, College of Medicine, University of Utah, Salt Lake City)
}

(Received for publication November 2, 1948)

Changes in the free erythrocyte protoporphyrin, plasma iron, serum iron-binding capacity and plasma copper in normal individuals and in various diseases associated with anemia have been investigated previously in this laboratory (1). The present observations were carried out to determine the "chemical pattern" of the blood in the pregnant state.

\section{METHODS}

The hematological methods used have been described previously (2). Free erythrocyte protoporphyrin was measured according to the method of Grinstein and Watson (3). The method of Barkan and Walker (4) was used for the measurement of serum iron. The ironbinding capacity of the serum was determined by a modification (5) of the method of Schade and Caroline (6). Plasma copper was determined according to the procedure of Cartwright, Jones and Wintrobe (7).

Eighty-six pregnant women were studied. The determinations were made at monthly intervals during pregnancy and the postpartum period. Thirty-one women were studied only once, 32 were followed for two months, 15 for three months, five for four months, and three for five months. In the entire study 139 determinations of packed red cells were made, 89 erythrocyte protoporphyrin determinations, 137 serum iron determinations, 129 plasma copper determinations, and 74 determinations of the serum iron-binding capacity. Sixteen women received ferrous sulfate by mouth during a part of the study. The values in this group showed no significant deviation from those in patients not receiving specific therapy. Nevertheless, the values obtained during the period of iron administration have not been included in the data presented in the figures. Placental blood was collected from the umbilical vein immediately after delivery of the placenta.

In this laboratory, the following are the values found in normal females: serum iron $104.3 \pm 36.4 \mu \mathrm{g}$ per cent, iron-binding capacity of the serum $371 \pm 35.9 \mu \mathrm{g}$ per cent, plasma copper $122.7 \pm 10.6 \mu \mathrm{g}$ per cent (1). Observed values for free erythrocyte protoporphyrin have shown a skew distribution and the geometric mean \pm two standard deviations has been found to be 34 (14 to 83)

1 Aided by grants from the United States Public Health Service and the Upjohn Company, Kalamazoo, Michigan. $\mu \mathrm{g} / 100 \mathrm{ml}$. of red blood cells. The normal subjects were not usually examined completely but they were apparently healthy and the hematologic determinations including the red cell indices were within normal limits in all instances.

\section{RESULTS}

Volume of packed red cells. The changes in the volume of packed red cells during pregnancy can be seen in Figure 1. During the first trimester, there was little deviation from the normal mean.

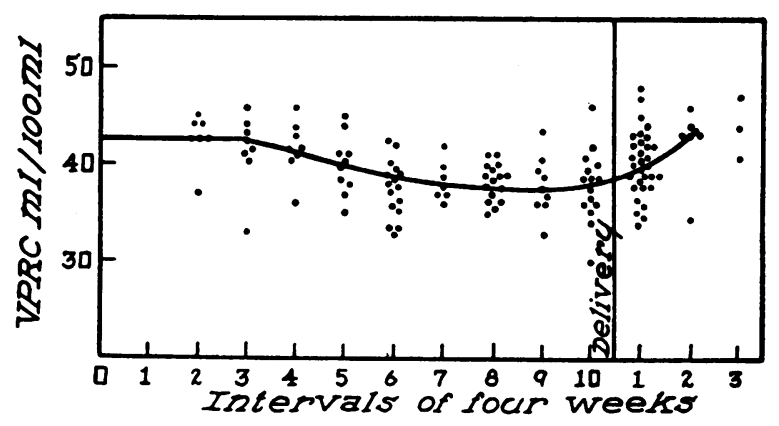

Fig. 1. Volume of Packed Red Cells (VPRC) during Pregnancy and the Postpartum Period

This was followed by a gradual decrease in the percentage of packed red cells. The lowest values were obtained in the last trimester, during the latter half of which the mean was found to be $37.9 \mathrm{ml} . / 100 \mathrm{ml}$. as compared with 42.5 during the first trimester. During the postpartum period a return to values found in non-pregnant women took place within the first two months.

Erythrocyte protoporphyrin. The trend of the free erythrocyte protoporphyrin during pregnancy can be seen in Figure 2. There appeared to be a slight increase in the mean value during each successive month but only five determinations were above, and only slightly above, the upper limit of normal.

Analysis of the relationship of the free erythrocyte protoporphyrin and the mean corpuscular 


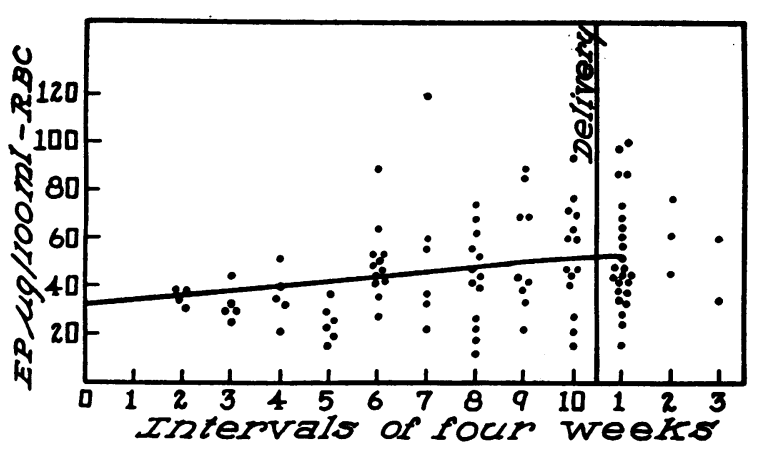

Fig. 2. Free Erythrocyte Protoporphyrin (EP) DURing Pregnancy and the Postpartum Period

hemoglobin concentration during the last trimester of pregnancy, reveals a correlation coefficient of - 0.54. However, since the mean corpuscular hemoglobin concentration ranged only from 31 to 37 per cent with two-thirds of the values 33 or 34 per cent, this correlation cannot be regarded as significant.

Serum iron. In Figure 3, the values for serum iron are presented. In the first trimester, no change was observed. After this, there was a gradual decrease in the mean, reaching the lowest value in late pregnancy. Within the first three months of the postpartum period a return to normal occurred. There were wide individual variations at all stages.

Iron-binding capacity. The changes in the total iron-binding capacity of the serum are presented in Figure 4. The values during the first 20 weeks were found to be within normal limits. During the second half of pregnancy the iron-binding ca-

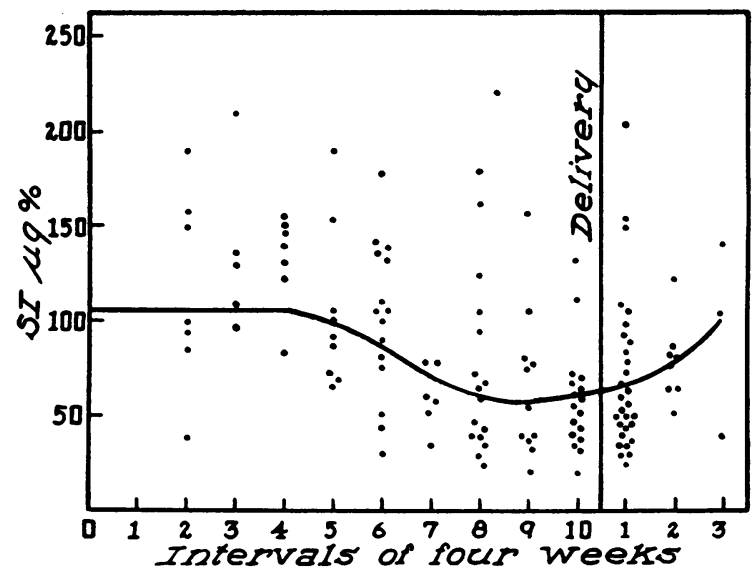

Fig. 3. Serum Iron (SI) during Pregnancy and the Postpartum Period pacity increased; the highest values were found in the last trimester. Within eight weeks after delivery, normal values were again attained. It should be noted that the iron-binding capacity increased at the time the serum iron diminished and the iron-binding capacity curve is the reciprocal of the serum iron curve.

Plasma copper. The results of the determinations of plasma copper are shown in Figure 5. Of the chemical constituents studied this was the first to change during pregnancy. The copper content of the plasma became elevated early in pregnancy and increased steadily until the third trimester, during which period it remained at a maximum until delivery. During the first two months of the postpartum period the values returned to the normal level.

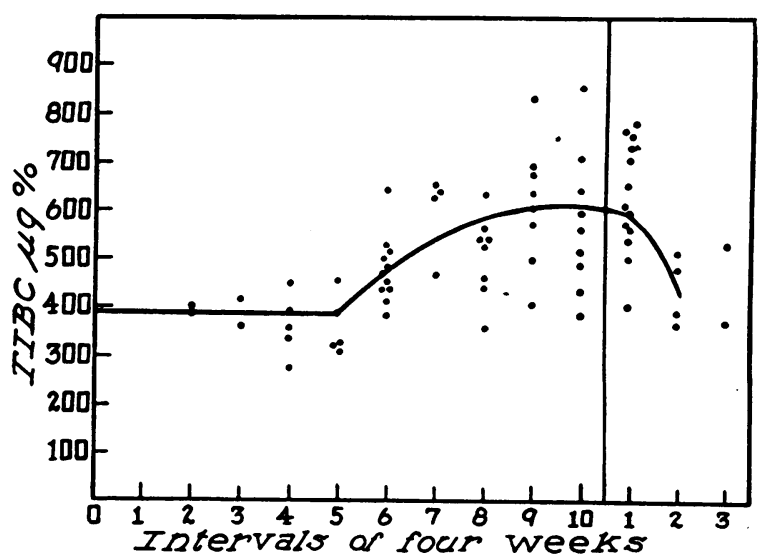

Fig. 4. Total Iron-Binding Capacity of the Serum (TIBC) during Pregnancy and the Postpartum Period

Placental blood. The placental and maternal serum iron and plasma copper are compared in Table I. The specimens were taken from the mothers at the time of delivery. As can be seen, the values for copper were considerably higher in the maternal blood than in the placental blood

TABLE I

Comparison of placental and maternal plasma - copper and serum iron

\begin{tabular}{|c|c|c|c|}
\hline Determination & No. of det. & Placental & Maternal \\
\hline $\begin{array}{l}\text { Plasma Copper } \\
\mu g \text { per cent } \\
\text { Serum Iron } \\
\mu g \text { per cent }\end{array}$ & $\begin{array}{r}14 \\
7\end{array}$ & $\begin{array}{r}75 \pm 14 \\
164 \pm 71\end{array}$ & $\begin{array}{r}260 \pm 42 \\
75 \pm 32\end{array}$ \\
\hline
\end{tabular}


TABLE II

Summary of the data

\begin{tabular}{|c|c|c|}
\hline Determination & $\begin{array}{l}\text { Normal } \\
\text { females }\end{array}$ & $\begin{array}{l}\text { 40th week } \\
\text { pregnancy }\end{array}$ \\
\hline 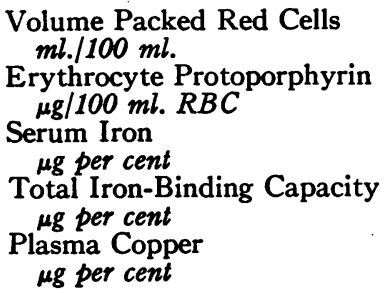 & $\begin{array}{l}44.5 \pm 0.4 \\
39(16-70)^{*} \\
104 \pm 5.5 \\
371 \pm 9.3 \\
123 \pm 1.5\end{array}$ & $\begin{array}{c}37.9 \pm 1.0 \\
53(16-93)^{*} \\
59 \pm 6.4 \\
583 \pm 50.3 \\
261 \pm 10.5\end{array}$ \\
\hline
\end{tabular}

Values represent mean \pm standard error of the mean.

* Since the frequency distribution curve is skewed an arbitrary range has been selected (1).

whereas the converse was true in regard to serum iron.

\section{DISCUSSION}

Certain alterations from the normal in copper, iron and iron-binding capacity of the serum have been observed during pregnancy, while no significant change has been found in free erythrocyte protoporphyrin. The results are summarized in Table II. The earliest change noted was an elevation in the plasma copper. This was followed in the middle of the second trimester by a decrease in the serum iron and a corresponding increase in the serum iron-binding capacity. The greatest changes in all three of these values were observed in the last trimester. In Table III morphologic and chemical studies on 22 women during the last trimester of pregnancy are given in detail. These findings are in accord with those of others (8-13).

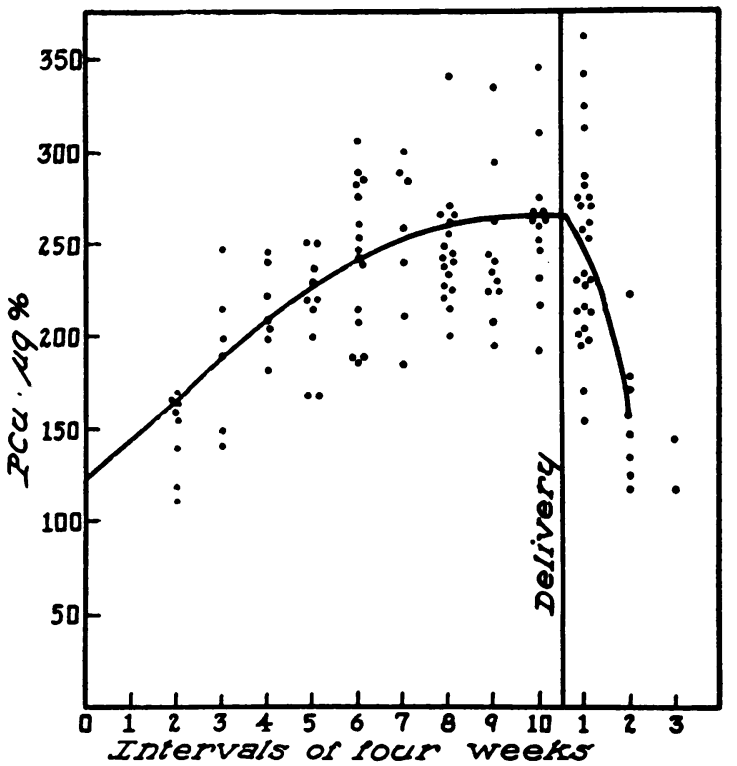

Fig. 5. Plasma Copper (PCu) during Pregnancy and the Postpartum Period

TABLE III

Detailed morphologic and chemical studies on 22 pregnant women during the last trimester of pregnancy

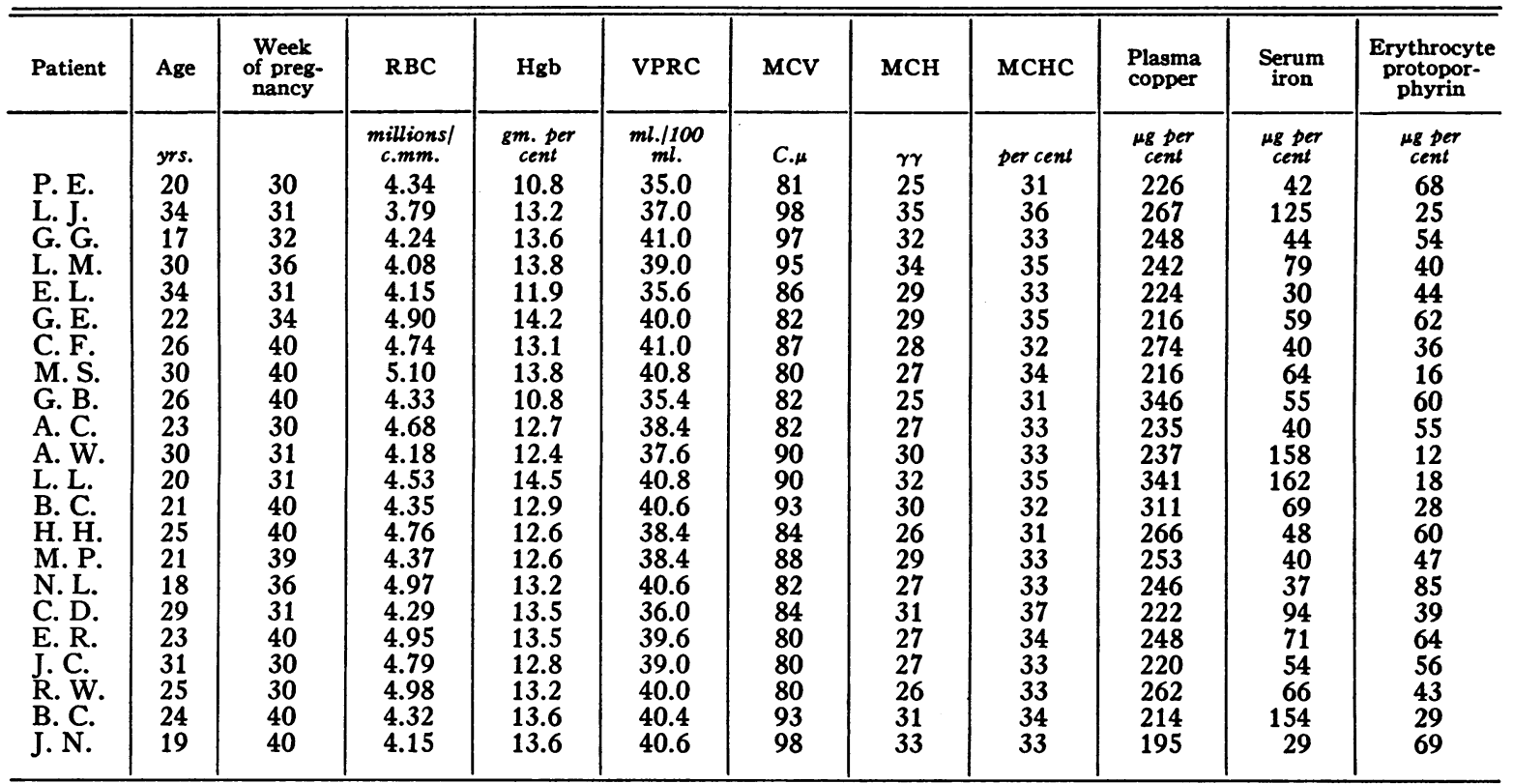


The changes noted during pregnancy differ in certain respects from those observed in various types of anemia (1). Thus, although as in the anemia associated with iron deficiency there was an increase in plasma copper, a decrease in serum iron and an increase in the iron-binding capacity of the serum, the serum iron values in pregnancy did not reach the extremely low levels seen in iron deficiency nor was there the marked increase in the free erythrocyte protoporphyrin seen in iron deficiency anemia. The chemical pattern does not correspond to that observed in the anemia of infection, where an increase in erythrocyte protoporphyrin and a decrease in iron-binding capacity of the serum occurs. Even in the presence of infection, the iron-binding capacity during pregnancy was found to remain elevated.

The increase in iron-binding capacity during the latter half of pregnancy occurs at a time when the demand for iron on the part of the fetus is greatest. The present observations reveal a close time correlation between the decrease in serum iron and the increase in iron-binding capacity. If the changes in these values were a function of variations in plasma volume, the deviations would of course be in the same direction. It may be that the elevation in the iron-binding capacity is part of the mechanism for increased iron absorption, mobilization and placental transfer and is analogous to the increase in iron-binding capacity of serum in iron-deficient states.

The elevation in plasma copper would seem to be independent of the changes in iron since there is no correlation in time or degree between these two values. One explanation that has been offered for the high values in the maternal blood is that the elevation of copper is related to the mechanism for mobilization of the element for placental transfer. This theory is based on the fact that copper storage in the tissues of the fetus, especially in the liver, is much greater than in the adult (14 16). It has beeen observed also that the copper content of placental arterial blood is greater than that of placental venous blood by 30 per cent (17). This suggests that there is a constant withdrawal of copper from the maternal blood via the placenta and storage in the fetus. It seems strange, however, that the high copper content of the fetal tisues should be associated with a low fetal plasma copper, while the high iron content of the fetal tissues is accompanied by a high serum iron in the fetus and a low serum iron in the mother.

A relationship between the elevated basal metabolic rate in pregnancy and the increased plasma copper has been suggested (13). Hypercupremia has been noted in non-pregnant patients with increased metabolism $(9,18)$. An elevation in serum precipitable iodine has been observed during pregnancy (19) over the same period of time in which an elevation of plasma copper was found in this study. Both of these changes are evident before there is a change in the basal metabolic rate. It is possible that the elevation in plasma copper is related to changes in endocrine equilibrium during pregnancy. It is clear that additional knowledge concerning the metabolism and functions of copper is needed before conclusions can be drawn concerning its significance in various clinical conditions.

\section{SUM MARY}

The free erythrocyte protoporphyrin, serum iron, serum iron-binding capacity, and plasma copper have been measured in 86 normal pregnant women. A decrease in the volume of packed red cells was noted in the latter part of pregnancy. There was no significant change in the free erythrocyte protoporphyrin, although a slight elevation of the mean was found during the later phase of pregnancy. A diminution in serum iron was evident during the latter part of pregnancy and at the same time the iron-binding capacity of the serum increased. Plasma copper values increased during the first trimester and remained elevated during the course of pregnancy. Normal values were regained during the first two months postpartum. Study of placental blood revealed low values for plasma copper while the serum iron level was higher than the corresponding values in the maternal blood.

\section{ACKNOWLEDGMENTS}

We are indebted to Miss Betty Tatting, Mrs. Darlene Kehl, Miss Mary Iles and Miss Pauline Black for technical assistance.

We wish to express our appreciation to Dr. Emil G. Holmstrom, Professor of Gynecology and Obstetrics, for his enthusiastic cooperation in this study.

\section{BIBLIOGRAPHY}

1. Cartwright, G. E., Huguley, C. M., Jr., Ashenbrucker, H., Fay, J., and Wintrobe, M. M., Studies on free erythrocyte protoporphyrin, plasma iron 
and plasma copper in normal and anemic subjects. Blood, 1948, 3, 501.

2. Wintrobe, M. M., Clinical Hematology. Lea and Febiger, Philadelphia, 1946, 2nd edition.

3. Grinstein, M., and Watson, C. J., Studies of protoporphyrin. III. Photoelectric and fluorophotometric methods for the quantitative determination of the protoporphyrin in blood. J. Biol. Chem., 1943, 147, 675.

4. Barkan, G., and Walker, B. S., Determination of serum iron and pseudo-hemoglobin iron with $\mathrm{O}$ phenanthroline. J. Biol. Chem., 1940, 135, 37.

5. Cartwright, G. E., Black, P., and Wintrobe, M. M., Chemical, clinical and immunological studies on the products of human plasma fractionation. XXXIX. The anemia of infection. J. Clin. Invest., 1949, 28, 86.

6. Schade, A. L., and Schade, Caroline L., An ironbinding component in human blood plasma. Science, 1946, 104, 340.

7. Cartwright, G. E., Jones, P., and Wintrobe, M. M., A method for the determination of copper in blood serum. J. Biol. Chem., 1945, 160, 593.

8. Holly, R. G., Anemias of pregnancy. Staff Meet. Bull. Hospitals of the University of Minnesota, 1946, 17, 281.

9. Locke, A., Main, E. R., and Rosbash, D. O., The copper and non-hemoglobinous iron contents of the blood serum in disease. J. Clin. Invest., 1932, 11, 527.
10. Sachs, A., Levine, V. E., Griffith, W. O., and Hansen, C. H., Copper and iron in human blood: comparison of maternal and fetal blood after normal delivery and after caesarian section. Am. J. Dis. Child., 1938, 56, 787.

11. Sachs, A., Levine, V. E., and Fabian, A. A., Copper and iron in human blood. Arch. Int. Med., 1935, 55, 227.

12. Laurell, C. B., Studies on the transportation and metabolism of iron in the body with special reference to the iron-binding component in human plasma. Acta physiol. Scandinav., 1947, 14, Suppl. 46.

13. Nielson, A. L., On serum copper. IV. Pregnancy and parturition. Acta med. Scandinav., 1944, 118, 92.

14. Morrison, D. B., and Nash, T. P., The copper content of infant livers. J. Biol. Chem., 1930, 88, 479.

15. Cunningham, I. J., Some biochemical and physiological aspects of copper in animal nutrition. Biochem. J., 1931, 25, 1267.

16. Lindow, C. W., Peterson, W. H., and Steenbock, H., The copper metabolism in the rat. J. Biol. Chem., $1929,84,419$.

17. Neuweiler, W., Fetal absorption of copper from the placenta. Klin. Wchnschr., 1942, 21, 521.

18. Nielson, A. L., Serum copper; thyrotoxicosis and myxedema. Acta med. Scandinav., 1944, 118, 431.

19. Heinemann, M., Johnson, C. E., and Man, E. B., Serum precipitable iodine concentrations in pregnancy. J. Clin. Invest., 1948, 27, 91. 